\title{
Mapping Enugu city's urban heat island
}

\author{
Enete Ifeanyi Christian, ${ }^{1, ~}$, Okwu Virginia Ugoyibo ${ }^{2}$ \\ ${ }^{1}$ Dept. of Geography \& Meteorology, Nnamdi Azikiwe University, Awka \\ ${ }^{2}$ Dept.of Geography \& Meteorology, ESUT
}

\section{Email address:}

ifeanyienete@yahoo.co.uk(E. I. Christian)

\section{To cite this article:}

Enete Ifeanyi Christian, Okwu Virginia Ugoyibo. Mapping Enugu City's Urban Heat Island. International Journal of Environmental Protection and Policy. Vol. 1, No. 4, 2013, pp. 50-58. doi: 10.11648/j.ijepp.20130104.12

\begin{abstract}
The presence of a city has a major impact on its local environment in terms of the heat and water balance of the area. In particular, it has been widely observed that the centre of the urban area tends to be of the order of 4 to $6^{\mathrm{oC}}$ warmer than its rural surroundings (the urban heat island effect). This paper applied remote sensing data to map UHI phenomenon in Enugu urban. The selected area covered Enugu North; Enugu South; and Enugu East with a total area of 18704.25 hectares. The urban heat island was determined by using the land surface temperature (LST) information from thermal infrared band (Band 6) of landsat image with $120 \mathrm{~m}$ pixel resolution. A subset of landsat TM acquired on October, 2008 that covered Enugu city was used in this study. Erdas imagine 8.5 was the main software for image classification of urban land cover in 2008, while GIS-Grid calculator functions were used to derive land surface temperature. This study demonstrates the spatial variation of land surface temperature (LST) within urban blocks with temperature above $37^{\circ}$ Celsius. Urban impervious areas, highly populated areas, and areas with more anthropogenic activities were recognized to be areas with highest number of UHI- related pixels. The result revealed the effectiveness of remote sensing data application in analyzing UHI- land surface temperature relationship in Enugu.
\end{abstract}

Keywords: Land Surface Temperature, Thermal Infrared, UHI, Landsat, Erdas Imagines

\section{Introduction}

The future temperature change for Nigeria was projected by the analysis group at the University of Cape Town. The scenario suggests a warmer climate in the future. For instance, it projects a temperature increase of $0.04^{\circ} \mathrm{C}$ per year from now until $2046-2065$ periods, rising to $0.08^{\circ} \mathrm{C}$ per year after 2050 (BNRCC, 2011). Apart from the changes in average temperature, the number, intensity and duration of heat waves, extreme precipitation events and drought is expected to increase.

Urban areas in Nigeria will generally experience the same exposures to climate as their surrounding Country side, the urban setting- its form and socio-economic activity can alter exposures as well as impacts at the local scale. Built-up areas in the cities create unique microclimate due to the replacement of natural vegetation with artificial surfaces. This affects air temperature, wind direction and precipitation patterns, amongst others.

The impact of heat waves is particularly strong in cities and towns. Urban heat Island (UHI) can be defined as the increased temperature of the urban air compared to its rural surroundings. The temperature difference can be up to $10^{\circ} \mathrm{C}$ or more (Oke, 1982). The difference is particularly more at night. Even relatively small towns can experience a considerable UHI (Steenereld et al., 2011). Urban heat island magnitude of $2^{\circ} \mathrm{C}$ has been recorded for Enugu Urban (Adinna et al., 2009, Enete et al., 2012).

The impacts of these changes will not be different in Enugu City, as climate change is expected to affect all of these components, exacerbating some of them and lessening others. This study, therefore, seeks to map out risk areas of urban heat island effects and heat waves in Enugu city; with the objective of determining the human health implications of UHI and heat waves. Climate change mitigation measures in our cities will limit the magnitude and rate of related events in the future, but they will not prevent them. As such, proactive adaptation to climate change in our urban centers become more imperative (EEA, 2010a). 


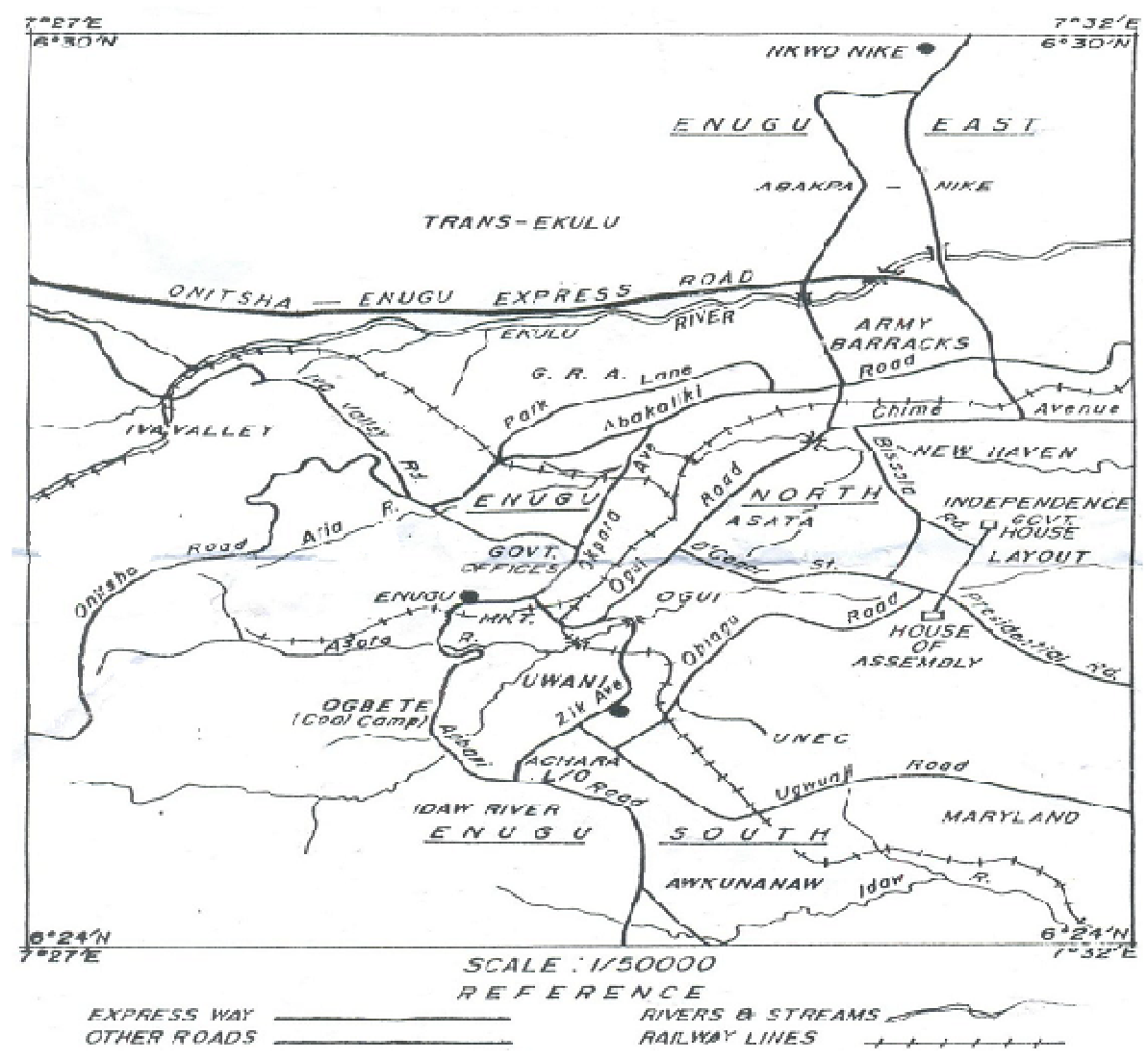

Fig 1. Map of Enugu Urban(Source: Ministry of Lands Survey Enugu)

\section{Study Area}

Enugu State is one of the states in southeastern Nigeria. Its capital is Enugu. The state was created in 1991 from the old Anambra State. Enugu state is located within latitude $6^{0} .00^{\prime} \mathrm{N}$ and $7^{0} .00^{\prime} \mathrm{N}$ and longitude $7^{0} .00^{\prime} \mathrm{E}$ and $7^{\circ} .45^{\prime} \mathrm{E}$. The state is called the Coal City State because of the discovery of coal in a commercial quantity in Enugu Urban in 1909. Enugu was then the capital of East Central State of Nigeria. Some of the important towns in the State are Enugu Urban, Oji, Udi and Nsukka Urban. The state shares borders with Abia State and Imo State to the south, Ebonyi State to the east, Benue State to the northeast, Kogi State to the northwest and Anambra State to the west. Enugu State is made up of 17 local government areas. Enugu Urban which is the study area is made up of Enugu East, Enugu North, and Enugu South (figure 1). Enugu Urban is located within latitude $6.24^{\circ} \mathrm{N}$ and $6.30^{\circ} \mathrm{N}$ and longitude $7.27^{\circ} \mathrm{E}$ and $7.32^{\circ} \mathrm{E}$. It is an hour's drive from Onitsha, one of the biggest commercial cities in Africa and 2 hours drive from Aba, another very large commercial city, both of which are trading centers in Nigeria. Enugu Urban shares boundary with Igbo Etiti and Isi-Uzo Local Governments in the north, Udi local Governments in the west, Nkanu West Local Government in the south and part of Nkanu East Local Government Area in the east. There are 18 prominent residential areas in the Urban. These are Abakpa, TransEkulu, Nike, GRA, Ogui, Asata, New Heaven, Obiagu,
Ogbete, Iva valley, Independence Layout, Achara Layout, Ugwuaji, Maryland, Awkanaw, Uwani, Agbani, and Coal Camp. Enugu Urban is the most developed urban area in Enugu state.

The study area falls within the humid tropical rain forest belt of Southeastern Nigeria. It has two seasons, the raining season and the dry season. The rainy season which is characterized by heavy thunderstorms lasts from April to October with the South Westerly moisture accompanied by air mass moving northwards into the city. The turbulent runoff result in leaching, sheet erosion and eventually gullies (Akabuike, 1990). The mean temperature varies from about $20.30^{\circ} \mathrm{C}$ to about $32.16^{\circ} \mathrm{C}$ in the dry season and rainy season respectively, (Akabuike, 1990). During the dry season the humidity is lower than in the rainy season. Temperature is most often high during the day and low during the night. This results in high evaporation rate during the day. Harmatten which occurs between the months of November and February is always accompanied by poor visibility mostly at night and early in the morning.

The rivers and streams which flow from the Udi hills dissect the study area into several sections. Thus there are rivers such as Ekulu, Idaw, Asata and Nyaba Rivers which separates Enugu South from Nkanu East. These rivers have many tributaries; the study area is generally marked by low land, slopping towards Enugu South Local Government Area and the Southern part of Enugu East Local Government Area. The elevations are between 182.88 meters and 219.45 meters above the sea level 


\section{Literature Review}

An increase in the mortality rate is the most dramatic impact of heat waves. There will be greater mortality caused by heat stress, and a shift in tourist destinations (McCarthy et al., 2001). There will also be an increase in electric cooling demand reduced energy supply reliability, decreased cold- related human morbidity and mortality along with reduced heating energy demand, increased flood, landslide, avalanche, and mudslide damage. Increased flood runoff could increase recharge of some flood plain aquifers and turn increase pressure on government and private flood insurance systems and disaster relief. There will be more damage to build foundations caused by ground shrinkage, decreased water resource quality and quantity and increased risk of forest fire. There are also expected to be some indirect effects due to crop damage by heat, water or pests and increased migration pressure as people move to more climatologically acceptable regions (McCarthy et al., 2001). Exposure to hot weather can also have other negative impacts on human health and wellbeing. Humans depend on the body's capability to maintain internal temperature at around $37{ }^{\circ} \mathrm{C}$. The principle mechanisms to prevent thermal stress are sweat production, increased cardiac output and redirection of blood flow to the skin (Hajat et al., 2010).Diminished or delayed physiological responses cause people to be extra sensitive to heat exposure. In particular, the elderly, young children and those using certain medication are sensitive to heat (Kovats and Hajat, 2008) as well as pregnant women.

In addition, socio-economic and behavioral factors enhance sensitivity to heat at the community level. Such factors include gender, social isolation, homelessness, lack of mobility, alcohol use, inappropriate dressing, intensive outdoor labour and low income or poverty (Kovats and Hajat, 2008; Hajat et al., 2010; Wilhelmi and Hayden, 2010). In many cases, in particular in cities, a number of those factors act together. For example, in low income groups people are more likely to be obese and have inadequate housing (Kovats and Hajat, 2008). Elderly people are more likely to be socially isolated, to be less mobile and to suffer from chronic disease while also having reduced physiological responses (Luber and McGeehin, 2008; Martens, 1998; Hajat and Kosatky, 2009).

People can, nevertheless acclimatize to heat to a certain extent. Initial physiological acclimatization is fairly fast and may occur after several days through increased sweating (Martens, 1998; Haines et al., 2006). However, even with more comprehensive and long term acclimatization and change of habits, temperature and humidity above certain local and individual thresholds can place stress on people with health implications.

Since geographic location and average temperature are closely linked, mortality related to heat seems to be linked with geographic position (Keatinge et al., 2000; Baccini et al., 2008; Martiello and Giacchi; 2010). The comfort temperature or heat thresholds at which the mortality rate is minimal, is associated with the average temperature that communities experience (Marten; 1998) and is indeed high in areas closer to the equator (Baccini et al., 2008; Hajat and Kosatky; 2009). However, there is no clear relationship between geographic location and the rate of increase of mortality once the comfort temperature is exceeded.

High temperatures during the night play a decisive role for the serious health effects during heat waves. Hot days without the relief of cool nights and subsequent exhaustion increase the effects of UHI (Grize et al., 2005; Kovats and Hajat, 2008; Dousset et al., 2011). Beyond the direct health impacts of thermal stress, other potential effects of heat on health, socio-economic and environmental impacts include:

i. Impact on well-being (Psychological impact; increased violence and social unrest).

ii. Impacts on water resources (water pollution caused by a combination of low water flow and heat; water shortage; changes in patterns of vector-borne diseases).

iii. Impacts on economy and infrastructure (reduced productivity of workers in conditions of extreme heat; increased hospital admissions and pressure on care services, decreased demand for heating, failure of power supplies (Wilby, 2008; Schauser et al., 2010; EEA; 2007;).

iv. Changes in patterns of vector -bone diseases.

\section{Methodology}

The major variable needed for this research include; temperature to determine areas of higher temperature. Satellite imagery was used for this purpose. The first step in the analysis was to make the land-cover classification using the Erdas imagine. In the study, supervised classification was employed to categorize the imagery into built-up, vegetation, water body, bare soil, shrubs and paved surfaces. The classification result was used to provide the emissivity of the land-cover categories. Emissivity was then used to estimate the land surface temperature from brightness temperature value in the thermal band image. Finally, the heat island impact was analyzed.

However, the land surface temperature is influenced by the geographic conditions such as the climate and weather at the time in the area, so it is difficult to compel the temperature itself to indicate the heat island impact within the city. The normalized surface temperature was prepared using the following steps as outlined by (Weng, (2003):

Step. I : Conversion of Digital number (DN) to spectral radiance $(\mathrm{Lx})$

$\mathrm{Lx}=(\mathrm{Lmax}-\mathrm{Lmin})($ Qcalmax - Qcalmin $) *($ Qcal. Qcalmin) + Lmin

Where Q Calmin $=1$

Qcalmax $=255$

Qcal $=$ DN (built-up $1=81$, built-up $2=89$, forest $1=58$, Forest $2=54$, Farmland $=69$ )

Lmin and Lmax are the spectral radiance for band 6 at DN 1 and 255 respectively. 
Stept: 2 Conversion of the spectral Radiance to temperature using the following formula:

$\mathrm{T}=\mathrm{K}_{2} / \ln \left(\mathrm{K}_{1 /} \mathrm{L}_{\mathrm{x}}+1\right)$

Where: $\quad \mathrm{T}=$ Effective as satellite temperature in Kelvin

$\mathrm{K}_{1}$ = Calibration Constant +1 in Watts (666.09)

$\mathrm{K}_{2}=$ Calibration Constant +2 in $\mathrm{K}$ (1283.7)

$\mathrm{L}_{\mathrm{x}} \quad=$ Spectral radiance in watts

Step 3: Computation of the emissivity corrected surface temperature using the formula:

$\mathrm{T}_{\mathrm{s}}$

$\mathrm{T} /\left\{1+\left(\wedge_{\mathrm{t}} / \alpha\right) \operatorname{InE}\right\}$

Note that:

(a) Thermal infrared band of land sat/ETM is $(10.44-12.42 \mathrm{NM})=11.43$

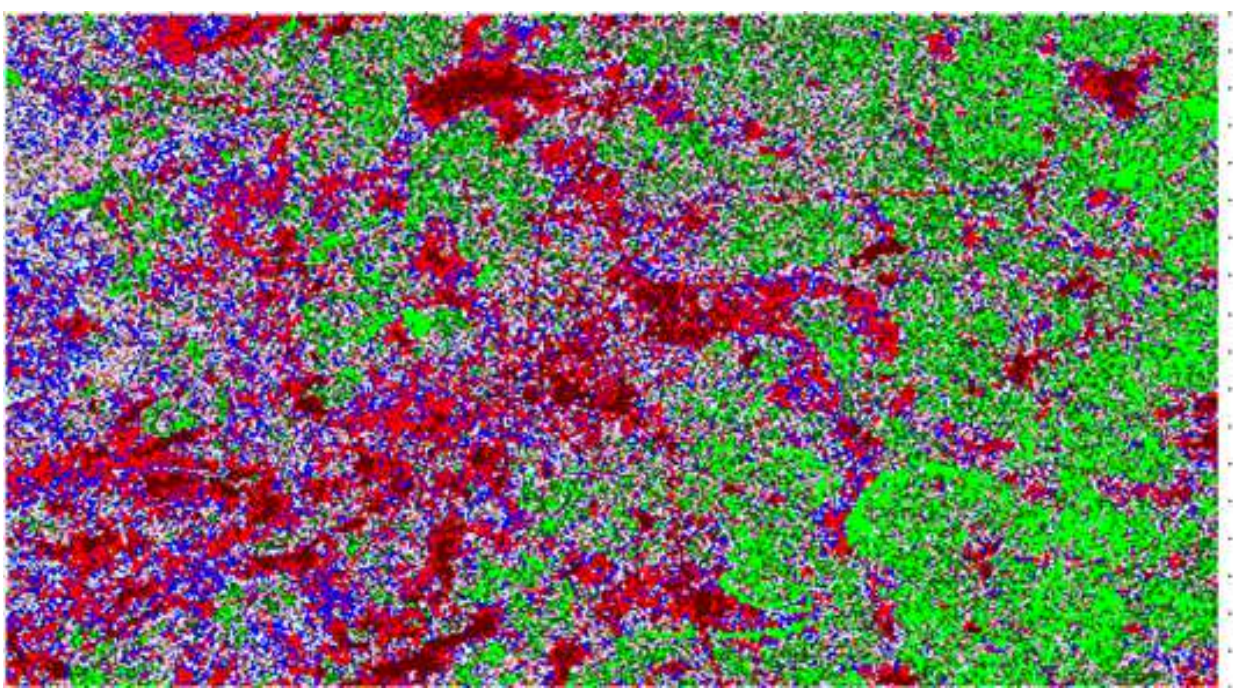

Fig 2. Imagery of Enugu Urban
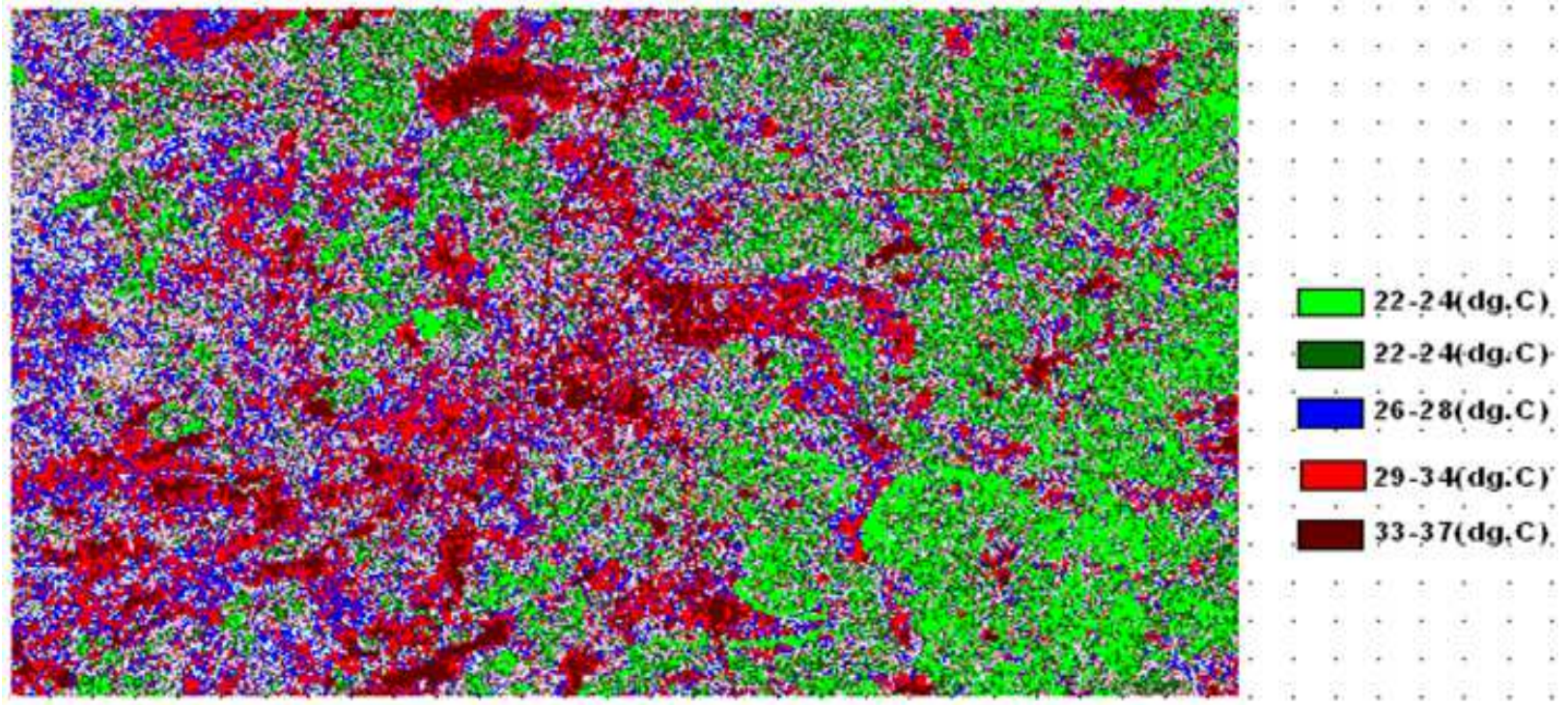

Fig 3. Temperature ranges for Enugu
Forest 1

Forest2

farm lands/Agric Areas

Built-Up-Areas1

Built-Up-Areas2
Urbanization and human activities essentially alter the the surrounding air. The outstanding features of urban figures 2 to 7 , which reveals areas with higher tem (ences in Enugu city. 


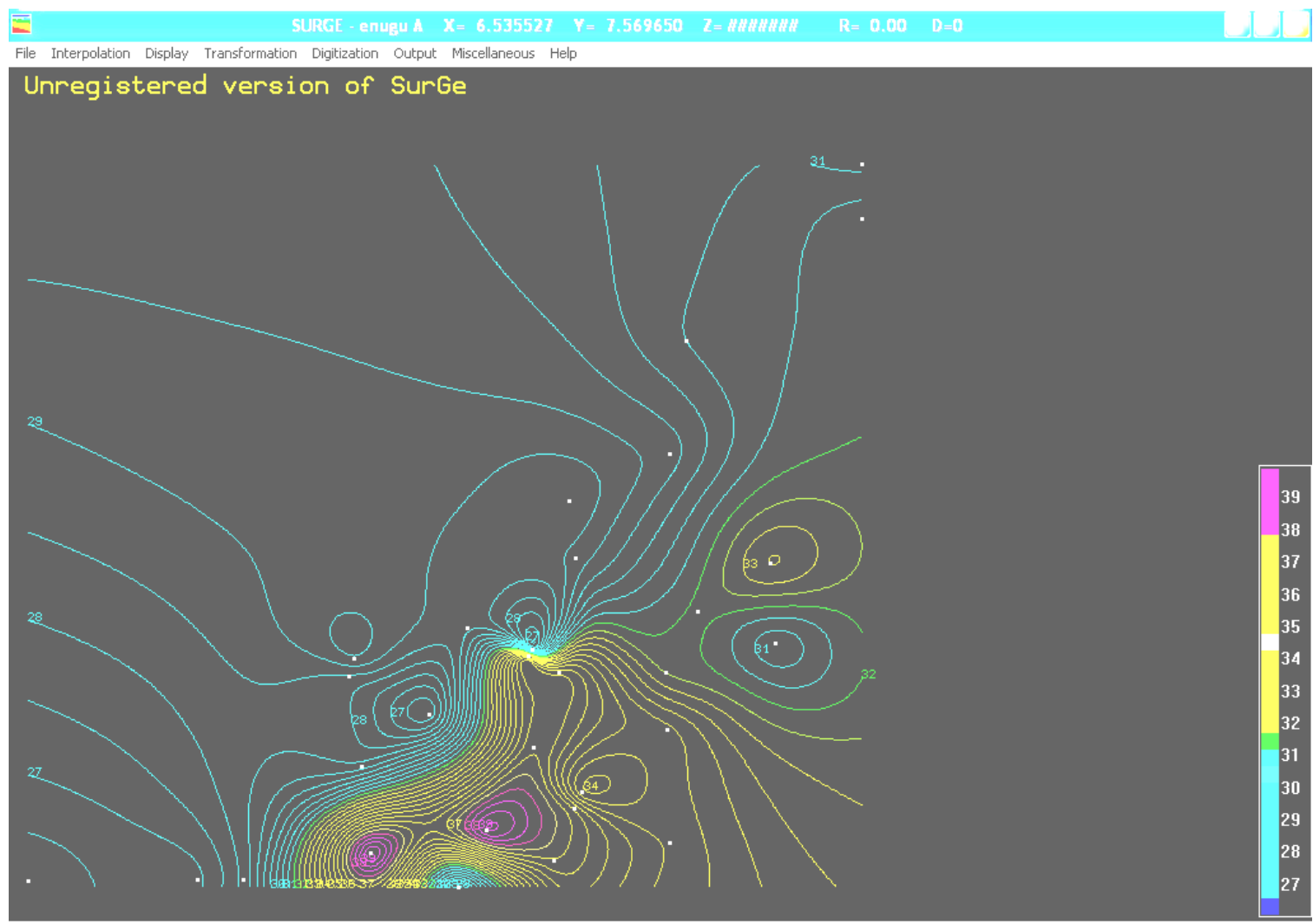

Movejzoom map ... use arrow keys and Pgup, PgDn ... press Enter to digitize map

$-$

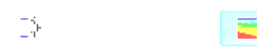

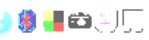

Fig4. Isotherm

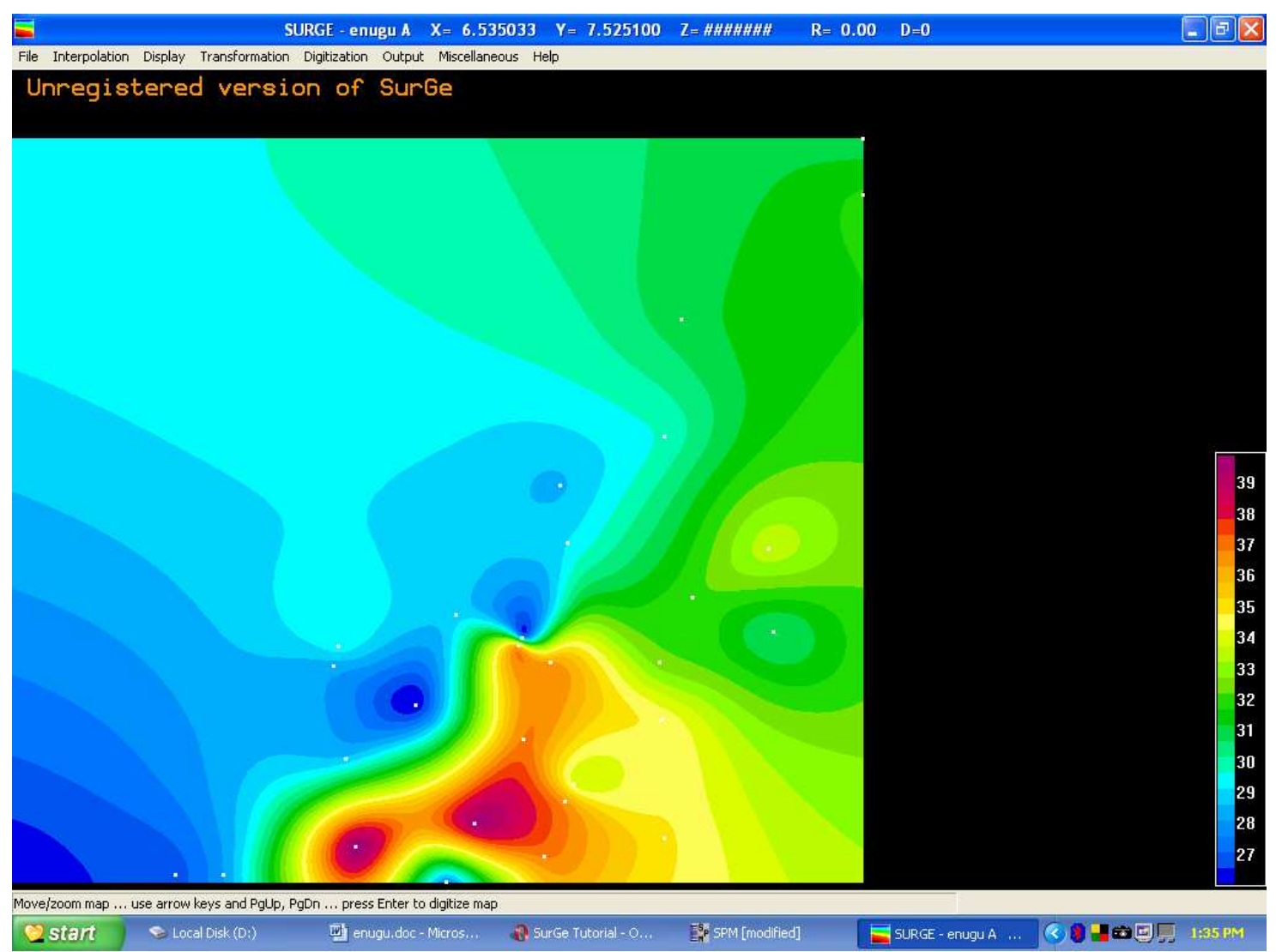

Fig5: Chloroplet 
To show the spatial variation of the temperature across the city. Figure 5 shows the result using the adjusted temperature (altitude and temporal) and inverse distance weighted option within ArcGIS. The dark red areas are $37^{\circ \mathrm{C}}$ and above, and the yellow areas $33^{\circ \mathrm{C}}$ with the grey areas grading in between.

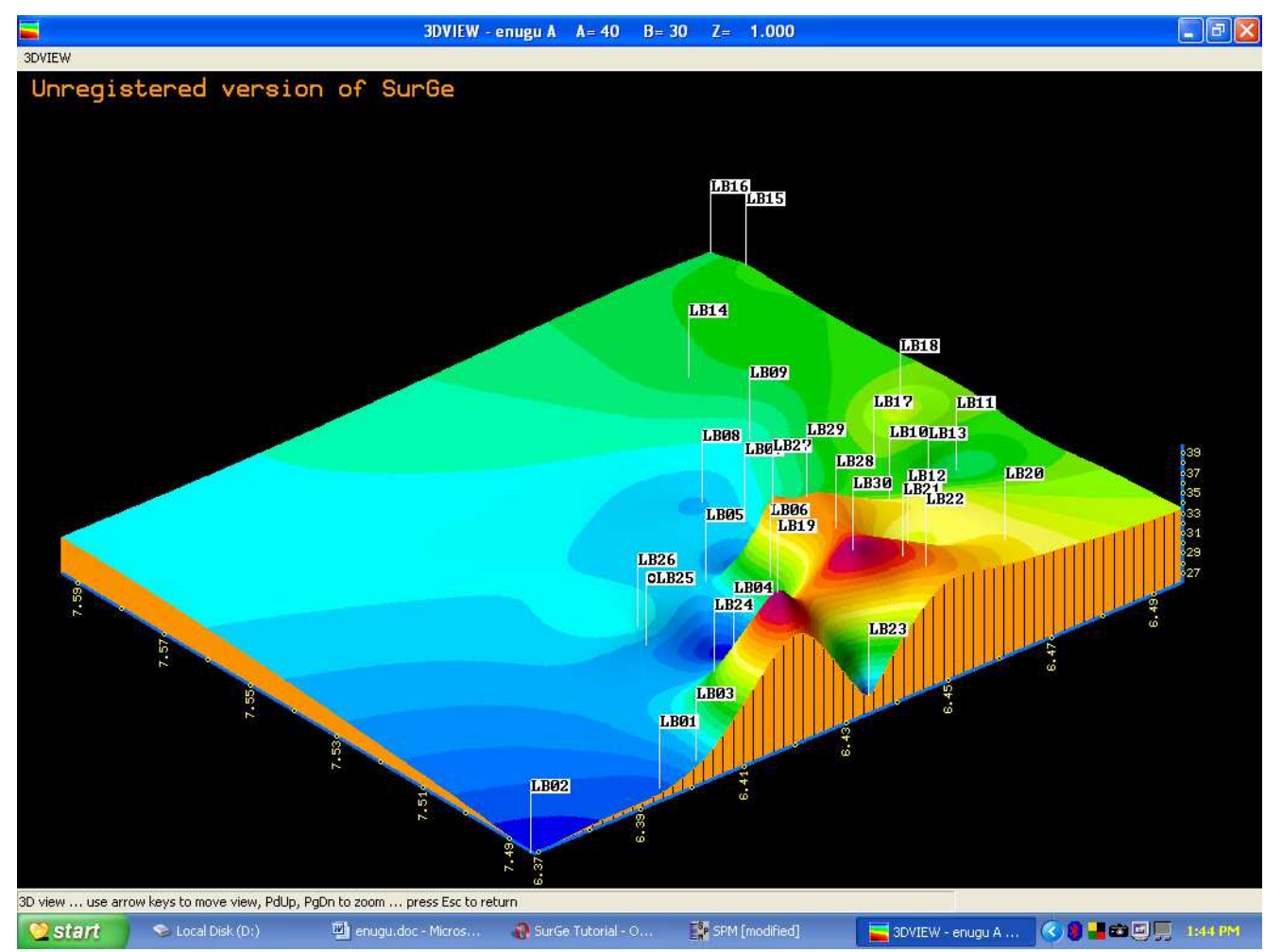

Fig6: Digital Elevation Model ( DEM) 1

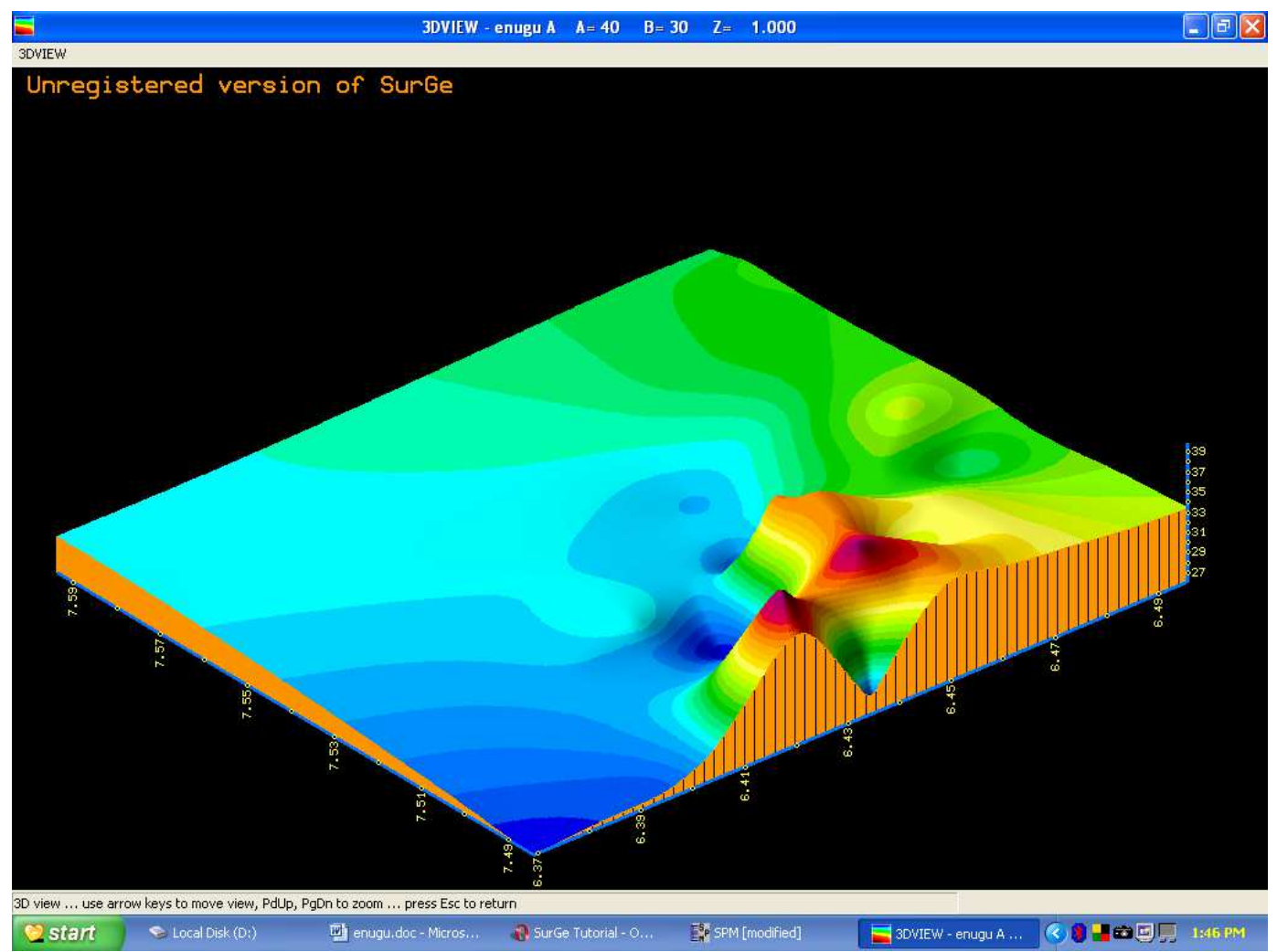

Fig7: Digital Elevation Model (DEM)2 
The intensity of UHI in towns and cities is influenced by the urban fabric and design (Oke, 1982; Airfield, 2003; Wilhelmi et al., 2004). Since the urban fabric shows large amounts of variation, the intensity of the UHI would reflect this. This can cause spatial variations of heat effects within cities as well as between cities (Smargiassi et al., 2009; Heusinkveld et al., 2010, Dousset et al., 2011; Knight et al., 2010). The hottest parts in cities and towns are generally those with numerous tall buildings, without green spaces and including areas generating large amounts of anthropogenic heat (EEA, 2006; Adinna et al., 2009; Enete et al., 2012).

It is evident from figures 2 to 7 that a thermal gradient progressed from the Central Business District (CBD) out into the Country side. Some hot spots or urban heat island can be easily identified. The most extensive UHI occurred in the Central part of the CBD, comprising Ogbete market, Ogui Road, Zik's Avenue, Okpara Avenue and Presidential Road. There were also many smaller UHI hot spots along highways (Enugu- Onitsha expressways, Enugu-PortHarcourt expressway) as well as residential Layouts of New Layout, New Heaven Abakpa, Emene, Uwani CoalCamp and Achara Layouts. These hot spots are prone to more UHI and heat wave effects.

However, there was no extensive UHI in the North- West as well as in the South- East of the city, except for a few smaller ones. Apparently, forestry and urban agricultural land uses in these areas prevented the development of UHI. The result shows clearly that commercial and industrial land uses exhibited the highest temperature was observed in forested areas, followed by residential land. The lowest temperature was observed in forested areas, followed by agricultural lands and pasture. This implies that urban development increased the temperature by replacing natural environment (forest, water and pasture) with non-evaporating, non-transpiration surfaces such as stone, metal and concrete surface.

\section{How Can Cities Adapt to Heat Stress?}

\subsection{The Use of Grey Infrastructure}

Due to the expected increase in the number of hot days and heat waves, it is anticipated that demand for air conditioning will increase. However, an increase in the use of air conditioners produces additional heat outside buildings and generates more greenhouse gases. Therefore, passive measures to provide cool spaces should be considered first - building designs that keep rooms cool via insulation (thick and well- designed walls, small windows, double glazing and the correct choice of materials) or blends and public space providing shade and natural ventilation. However, in the event that active cooling of building continues to be necessary, the most energy efficient air condition systems should be used and promoted through the Eco labeling Directive (EC, 2009) and awareness raising campaigns.

\subsection{The Use of Green Infrastructure}

Conservation and improvement in existing green and blue areas in cities and the creation of new spaces to ameliorate the urban heat island effect is hugely important and can have a number of additional benefits such as creating areas for recreation, biodiversity, filtering air and draining and storing water. Vegetation provides cooling through shading and enhanced evapotranspiration. Parks and open water areas are essential. Green and blue roofs lower temperature during dry seasons through insulation and enhancing evapotranspiration. Vegetation areas have a significant effect on the local climate as they incite the production of fresh and cold air, particularly at night, and have a thermally balancing effect during the day due to a high percentage of tress (EEA, 2013). Above all, this smart and integrated approach to spatial planning ensures that cities limited land is turned into areas capable of providing multiple functions for nature and society (EC, 2012a).

\subsection{Awareness and Behavior Change}

Awareness of the local population regarding effects of excessive heat on human health coupled with information on simple measures to prevent excessive heat stress enhances preparedness. Such measures can reduce sensitivity to heat exposure at the individual and community level. Simple heat warning advices from 'avoid drinking alcohol to' wear a hat can be very effective.

\subsection{Health Warning Systems and Heat Action Plans}

Awareness rising is usually one of the components of so called heat action or heat warning plans (Ebi et al., 2004: Hajat et al., 2010). The World Health organization Europe (WHO Europe) has published guidance on how to develop such plans (Barredo, 2009; Mathies et al., 2008). The development of a Heat Health Watch Warning System (HHWWS) can be considered as a long term option to address heat waves and other high temperature events.

\subsection{Stakeholder Involvement}

All relevant municipal stakeholders eg, Municipal departments, public health services, meteorological services, hospitals and other medical institutions have their own protocol of activities and the mandate to carry out these activities in the event of a heat wave. These stakeholders should meet regularly to assess how the changing climate could directly affect their constituents and to provide input on what is needed now to protect services and people in the future (NCVO,2012).

\section{Conclusion}

It is observed in this study that temperature and land use 
information can be directly derived from remotely sensed data, which provides a powerful way to monitor urban environment and human activities. This can effectively replace the traditional analogue system of urban studies. The present study explored the effects of urban heat Island and heat waves by mapping the risk areas in Enugu city and reviewing the human health impacts.

The use of grey infrastructure, awareness and behavior changes; and creation of health warning systems and heat action plans were advocated mitigation measures.

\section{References}

[1] Adinna, E.N., Enete, I.C, and Okolie, T. (2009). Assessment of Urban Heat Island and possible Adaptations in Enugu Urban using Land Sat/ETM. Pakistan Journal of Social sciences, 6 (1): 26-31.

[2] Arnfield, A. J (2003). "Two Decades of Urban climate research: A Review of turbulence, exchanges of Energy and the urban heat Island. International Journal of climatology $13: 1-26$.

[3] Baccin M., Biggeri, A Accetta, G. Kosatstky, T. (2008). "Heat effects on mortality in 15 European cities, Epidemiology, 19: 711-719.

[4] Barredo, J.I (2009). "Normalized flood losses in Europe: 1970-2006," Natural Hazards and Earth System Science 2009-02-09, 9(1)97-1045.

[5] Building Nigeria's response to climate change (BNRC) climate change adaptation strategy technical reports Nigeria. (CCASTR) Ibadan, Nigeria: Nigeria Environmental study/Action Team (NEST).

[6] Dousset, B., Govemelon, F., Laaidi, k., Zeghnoun, A. Giraudet, E., Bretin, P., Mauri, E., and Vandertorren, S (2011). "Satellite Monitoring of summer heat waves in the Paris metropolitan area, International Journal of Climatology, 31 (2): 313-323.

[7] Ebi K., Tisbury, T.J, Kalkstein, L.S, Robinson , L and Weiher, R. F (2004), "Heat watch/Warning System save lives; Bulletin American Meteorological Society; 2004 (85) 1067-1073.

[8] EC, (2000a) Regulation (EC) 1980/2000 of the European parliament and of the Council of 17 July 2000 on a revised community eco-label award scheme.

[9] EC, (2009a). Promoting sustainable urban development in Europe: Achievements and opportunities European Commission, Brussels.

[10] EC, (2012a). Green Infrastructure (http: llec.ecuropa.eu/ environment/natures/ecosystems/index en.htm) accessed 26 March, 2013.

[11] EEA (2006). Urban Sprawl in Europe: The ignored challenge, EEA Report No 10/2006), European Environment Agency.

[12] EEA (2007). Climate Change: The cost of inaction and the Cost of adaptation, EEA Technical report No 13/2007, European Environment Agency
[13] EEA (2012). Urban Adaptation to Climate change in Europe Challenges and Opportunities for cities. EEA Technical Report No 2/2012, European Environment Agency.

[14] EEA, (2010b). The European environment- State and outlook 2010: Thematic Assessment - Urban Environment, European Environment Agency.

[15] Enete, I.C. , Alabi, M.O and Chukwudeluzu, V.U(2012). Tree Canopy Cover variation effects on Urban Heat Island in Enugu City, Nigeria, Journal of Developing country studies, USA, 2(6):12-18.

[16] Grize, L., Huss, A., Thommen, O., Schindler, C and BraunFahrlander, C (2005), "Heat wave 2003 and Mortality in Switzerland", Swiss Medical Weekly, 135 (13-14): 200 -205.

[17] Haines, A., Kovats, R.; Campbell-lendrum, D. and Corvalan, C (2006) "Climate change and human health: Impacts, Vulnerability and Mitigation", The Lancet, 367 (9528): 2101-2109.

[18] Hajat, S and Kosatky, T. (2009) "Heat-related Mortality: A review and exploration of heterogeneity; Journal of Epidemiology and Community Health, 64(9): 753-760.

[19] Hajat, S. O' Connor, M and Kosatsty, T (2010). "Health effects of hot weather: from awareness of risk factors to effective health protection; Lancet 375 (9717)" 856-863.

[20] Heusinkeveld, B.G., Van Hove, L.W.A., Jacobes, O M.J., Steeneveld, G.J., Elbers, J.A., Moors, E.J. Holtslag, A. A. (2010). "Use of a Mobile platform for assessing urban heat stress in Rotterdam. Proceedings of the $7^{\text {th }}$ conference on biometeorology held at Albertludwigs University between 12-14 April 2010.

[21] Keatinge W. R., Donaldson, G.C., Cordiole, E., Martinelli, M.., Kunst, A.E., Mackenback, J.P., Nayha, S. and Vuori, I(2000). "Heat related mortality in warm and cold regions of Europe: Observational study' BMJ (Clinical Research Ed), 321 (7262): 670-673.

[22] Knight, S. Smith, C and Roberts, M. (2010). "Mapping Manchester's urban heat Island, Weather 65(7): 188-193.

[23] Kovats, R.S. and Hajat, S(2008), "Heat stress and Public Health: A critical Review; Annual Review of Public Health, 29 (1): 41-55.

[24] Luber, 9 and McGeehin, M (2008), "Climate change and extreme heat events" American Journal of Preventive Medicine, 35(5): 429-435.

[25] Martens, W.J.M (1998). "Climate change, thermal stress and mortality changes. Social science and medicine, 46(3):331344.

[26] Martiello, M.A and Giacchi, M V. (2010). "Review article high temperatures and health outcomes: A review of the literature", Scandinavian Journal of Public Health, 38(8): 826-837.

[27] Mathies, F., Bickler, G., Cardenosa Marin, N and Hales, S. (2008). Heat - health action Plans- Guidance, WHO regional Office Europe, Copenhagen, Denmark.

[28] McCarthy, J.J.,Canziani,V.D., Osualdo,F., Leary, N.A., Dokken,D.J., White, K.S (ed.) (2001). Climate Change 2001:Impacts, Adapttation, and Vulnerability. Summary for policymakers 
[29] NCVO (2012). Climate change/Natural Council for Voluntary Organizations (http://www.ncrovol.org.uk/climatecnage) accessed 26 march,2013.

[30] Oke, T.R (1982). The Energetic basis of the urban heat island; Quarterly Journal of the Royal Meteorological Society; 108 (455) 1-24.

[31] Schauser, I., Otto, S., Schnciderbauer, S., Harvery. A., Hodgson, N., Robrecht, H., Morchain, D., Schrander, J.J. Khovanskaia, M., Celikyilmaz-Aydemir, G., Prutsch, A., and McCallum, S. (2010). Urban regions: Vulnerabilities, Vulnerability assessments by indicators and adaptation options for climate change impacts-Scoping study, ETC/ACC Technical paper, European Topic Centre on Air and Climate change, Bilthoven.

[32] Smargiassi, A. Goldberg, M.S., Plante, C., Fournier, M.., Baudouin, Y and Kosatsky, T (2009). "Variation of daily warm season workability as a function of Micro-Urban heat Islands," Journal of Epidemiology and Community Health, 63(8): 659-664).
[33] Steeneveld; G. J; Koopmans, S.; Heusinkveld, B G VanHove, L W.A and Holtslag, A.A. M (2011). Quantifying Urban heat Island effects and Human Comfort for cities of variable size and urban Morphology in the Netherlands, Journal of Geophysical Research, 116 (D20).

[34] Weng, O (2003). Fractal Analysis of Satellite Detected Urban Heat Islands effect. Photogrammetric Engineering and Remote Sensing, 69:555-566.

[35] Wilby R.L. (2008): Constructing Climate change scenarios of urban heat Island intensity and air quality, Environment and planning B: Planning and Design, 35(5) 902-919.

[36] Wilhelmi; O. V and Hayden, M.H (2010). Connecting People and place: A new framework for reducing Urban Vulnerability to extreme heath, Environmental Research letters, 5(1) 014021.

[37] Wilhemi O.V. Purvis, K. L and Harriss, R. C. (2004). Designing a geospatial information infrastructure for mitigation of heat wave hazards in urban areas, natural Hazards Review, 5(3):147. 